\title{
Putting the Brakes on the
} obestify plojenje

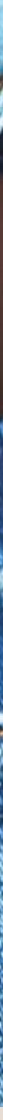

\section{Americans have been gaining weight at about} the same rate for the past 25 years. What former U.S. Surgeon General Richard Carmona characterized in 2003 as an obesity epidemic is affecting all groups, whatever their race, ethnicity, place of residence, or level of education. 
The epidemic is very costly. Obese individuals, on average, incur health care costs one-third higher than persons of normal weight, and costs for severely obese individuals are twice as high. And people who are severely obese remain the fastestincreasing group of Americans who suffer from obesity. ${ }^{1}$

Cutting the current rate of obesity in the United States in half-to the level in 1978-would reduce the burden of costly health problems, such as diabetes, hypertension, and heart disease; increase longevity and years of disability-free life; and significantly decrease Medicare and Medicaid costs. Savings to Medicare alone could reach $\$ 1.2$ trillion by 2030 . $^{2}$

What's driving the obesity epidemic? The fact that weight gain has been surprisingly similar across all groups suggests that the obesity battle must grapple with environmental factors. RAND work suggests three powerful, interacting influences:

- the economics of food

- the food-choice environment

- the way foods are marketed.

\section{Food: Cheaper + Easier = More}

As a share of disposable income, Americans have the cheapest food in history. ${ }^{3}$ Food is also easier and cheaper to prepare than ever before. Indeed, our average daily calorie intake of about 2,700 makes Americans among the world's heartiest eaters.

Americans are eating more healthy foods. But we have just added fruits and vegetables to our diets, rather than substituting them for high-calorie foods. Efforts to combat obesity need to reduce overall calories consumed, while also trying to nudge consumers away from calorie-dense foods toward healthier fare. ${ }^{3}$

\section{Food Expenditures as a Percentage of Disposable Income}

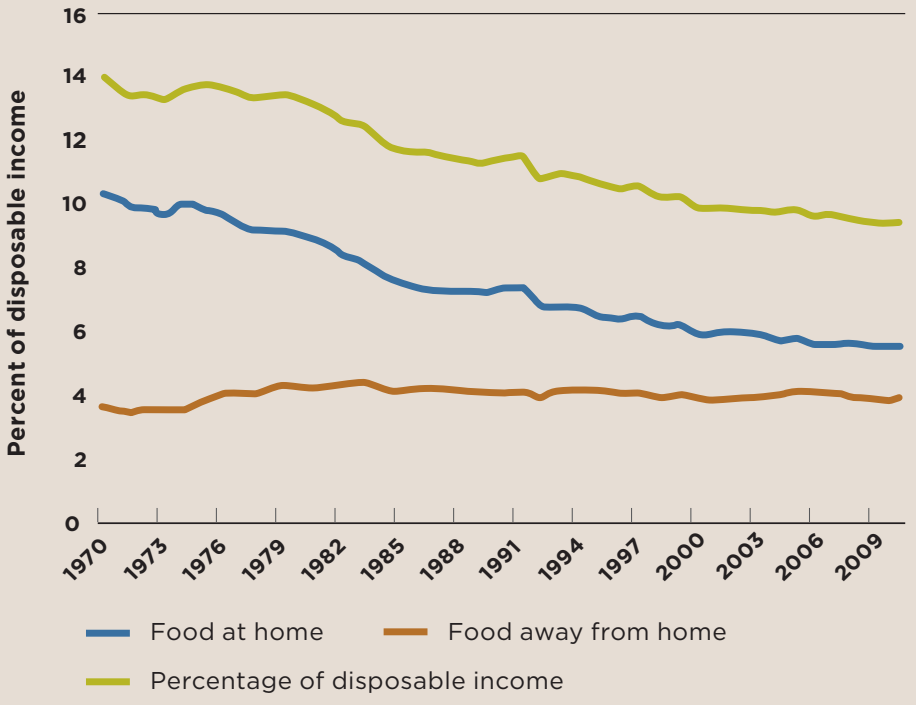

SOURCE: Economic Research Service of the U.S. Department of Agriculture.

\section{Changing the Choice Environment}

Arguably, one way to nudge consumers away from caloriedense foods is to make those foods hard to get. From this perspective, banning fast food seems like a promising tactic. But a yearlong experiment in Los Angeles that banned new fast food restaurants in a low-income neighborhood didn't have the intended effect. Residents were more likely to be obese than their counterparts in more affluent parts of the city, but the low-income neighborhood actually had fewer fast food restaurants than the wealthier neighborhood. Residents in both neighborhoods ate about the same amount of fruits and vegetables and exercised about as often. But residents in the lower-income area consumed more "discretionary calories" from candy and cookies.

Extending this analysis to more than 5,000 adults in Los Angeles County, researchers found little association between residents' diet and obesity rates and the proximity of fast food outlets, small convenience stores, or supermarkets. ${ }^{4}$ These findings suggest that the relationship between a neighborhood's food outlets and its residents' diet should not be viewed as one size fits all. Policies designed to enhance the choice environment need to be more nuanced, reflecting the patterns and cultures of the environments in which they are implemented. So, for example, policy effects in the highly motorized Los Angeles environment should not be generalized to more centralized areas-for example, New York or Chicago.

Another way to change the choice environment is to make healthy food easier to get. That's the approach underlying efforts to bring full-service supermarkets to "food deserts," where, it has been argued, residents have to rely on the calorie-dense food served up in convenience stores and fast food outlets. But does bringing a supermarket to a food desert really improve residents' health?

Plans to open a full-service supermarket in a lowincome, predominantly African-American community in Pittsburgh made it possible to begin answering that question. The community's first full-service grocery store in more than three decades opened in 2013, providing geographic access to fresh fruits and vegetables. By comparing this community with a similar community lacking a supermarket, researchers could explore how changes in the food environment affect the kind of food that residents buy and eat.

The study's findings were partially at odds with conventional wisdom. An initial assessment of shopping habits in both food deserts showed that more than three-quarters of residents already shopped at a full-service grocery and did not use neighborhood stores for food shopping. ${ }^{5}$ Researchers also found that the price of food had more 


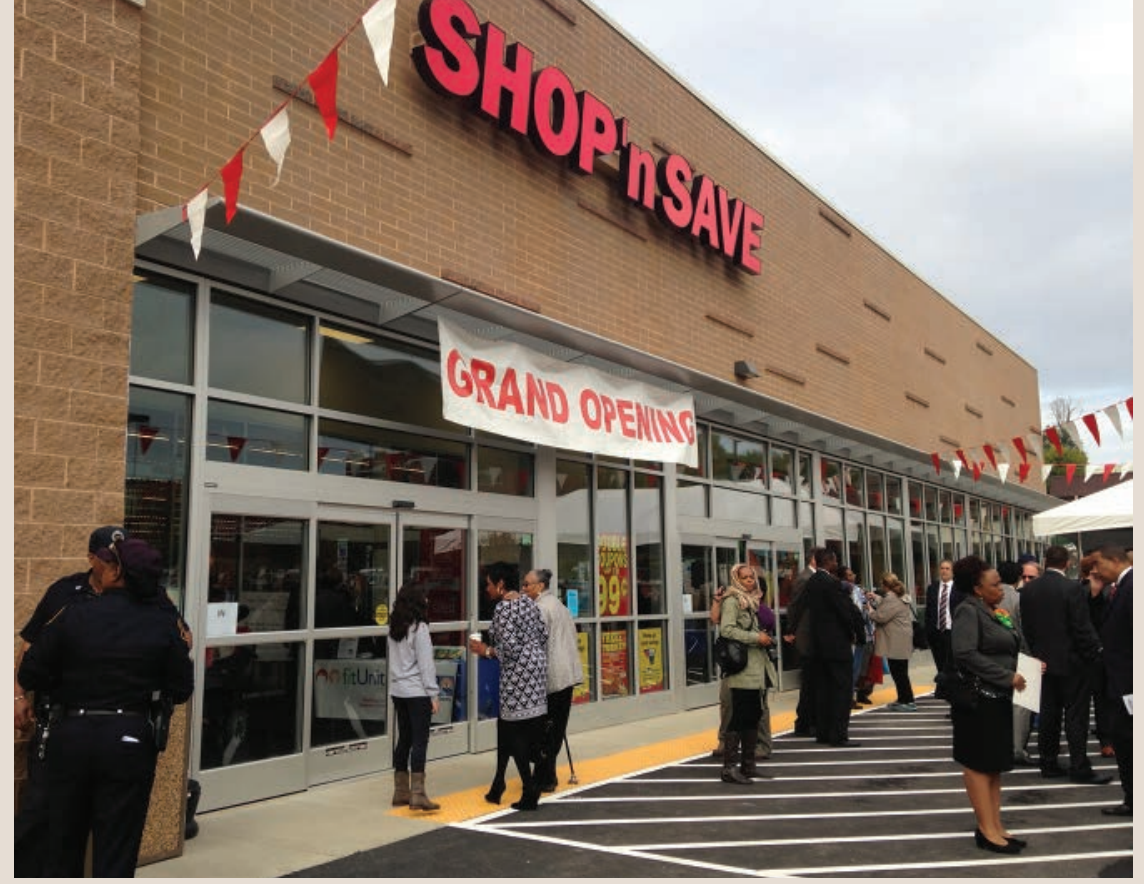

The opening of the supermarket in Pittsburgh

\section{Understanding the Power of Marketing}

Part of the rationale for putting supermarkets in food deserts is the assumption that if healthy food is available, people will buy it. But what influences the kind of foods that turn up in a shopper's basket? Public campaigns focusing on nutritional guidelines, diets, and food labels assume that, armed with proper information and motivation, people will consume fewer calories. Multiple RAND studies suggest that this assumption needs to be rethought.

The average American adult buys a meal or snack from a restaurant nearly six times a week. But consumers who are trying to eat smart aren't getting any support from the typical restaurant. Ninety-six percent of the entrees from more than 200 chain restaurants contain more calories, fat, and sodium than should be consumed in one

influence on shopping habits than did distance. In addition, residents who did their major food shopping at a low-priced store had a higher chance of suffering from obesity.

Marketing seemed to play a key role: Fruits and vegetables were equally available in high-price and low-price stores, but the high-price store actively marketed healthy foods, while the latter pushed junk foods. ${ }^{6}$ These initial findings suggest that actively marketing reasonably priced healthy foods might be more effective than just locating supermarkets in food deserts.

After the supermarket opened, the research team compared the residents of the two food deserts on several dimensions. Some aspects of residents' diet in the supermarket community improved (for example, they consumed less sugar and fewer calories), and they were more satisfied with their neighborhood as a place to live. But consumption of fruits and vegetables declined in both communities, and rates of obesity were unchanged. Residents who used the supermarket felt that they had access to a better selection of healthy, affordable foods, but their improved diet and increased satisfaction weren't associated with how often they used the supermarket.?

The researchers speculated that improved diet in the community with the supermarket was linked in some way to the opening of the supermarket, which spurred other neighborhood changes. The significant increase in neighborhood satisfaction was not directly related to dietary changes, but the opening of the supermarket prompted additional economic investment in the community. Until the exact mechanism related to how neighborhood changes may have influenced residents' diet is understood, it is not clear whether placing supermarkets in food deserts is a way to improve residents' diet and well-being without actually affecting obesity rates or whether this policy can become a powerful weapon in the national war on obesity. sitting. ${ }^{8}$ And despite pressure to increase their healthier offerings, restaurants aren't making meaningful changes.

But it is also the case that eating may be influenced more by environmental factors than by conscious choice. For example, end-aisle displays attract shoppers' attention, making these locations the stores's most valuable real estate. ${ }^{10}$ Manufacturers pay hefty fees to display their products in these locations.

Prominent displays of calorie-dense snacks present temptations that can be hard to resist. Arguably, these displays put consumers at risk because our impulsive choices from them are largely automatic, rather than conscious and deliberate. ${ }^{11}$ Store audits conducted for the food desert study revealed that markets are more likely to display low-nutrient foods in prominent places and that they are more likely to offer price discounts for these high-sugar, high-fat foods. Such marketing strategies were strongly associated with a higher body mass index (BMI) among

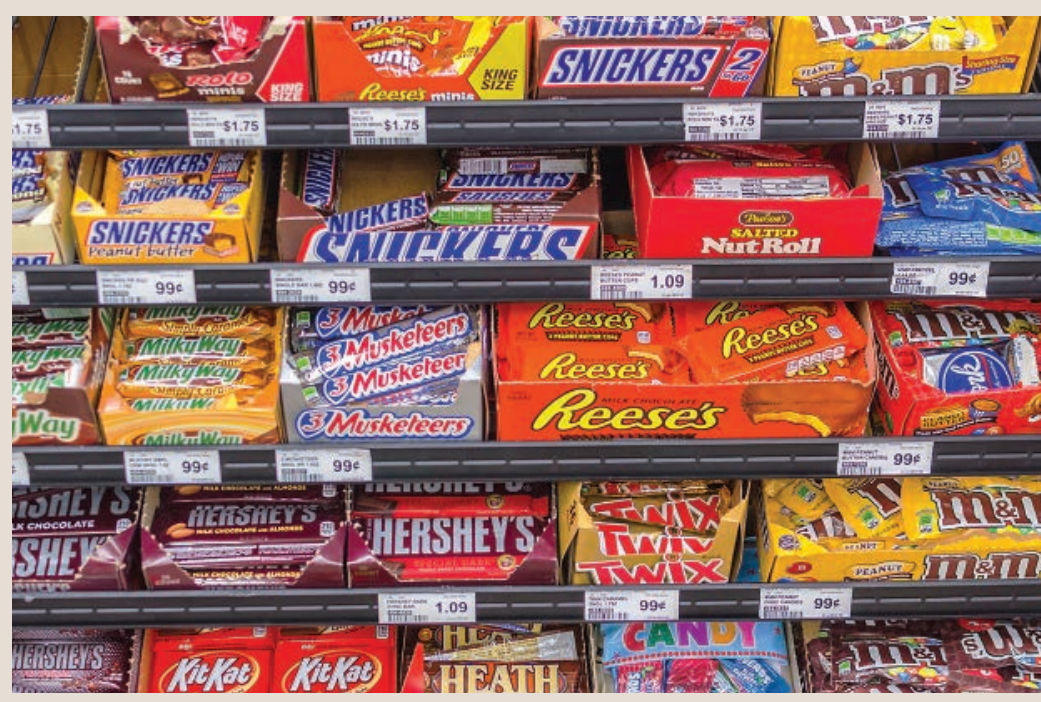




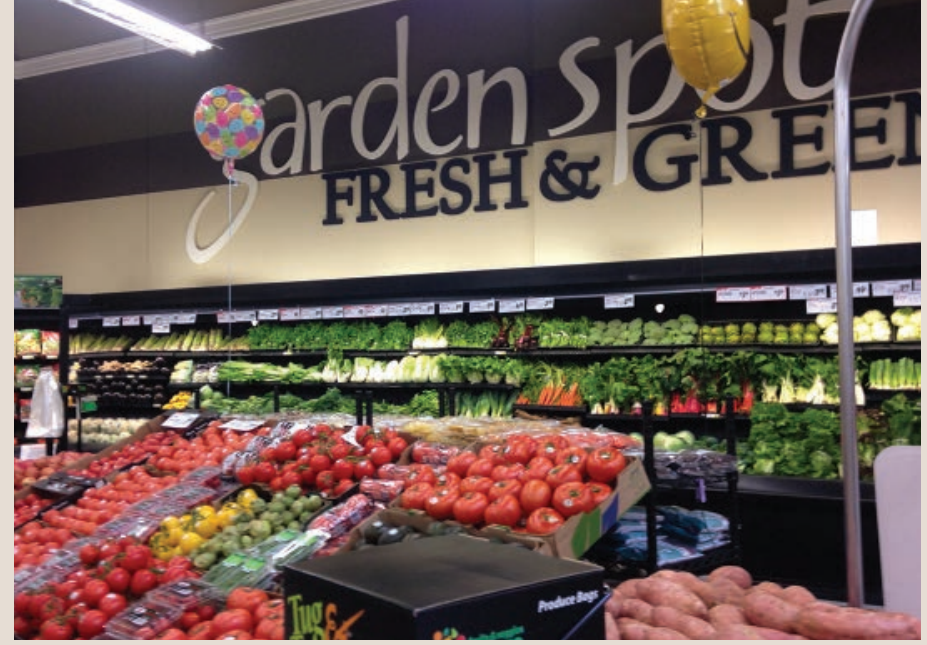

regular customers. ${ }^{6}$ (BMI is a widely used measure of body fat based on height and weight.)

Shopping lists seem to limit impulsive choices, and customers who used them regularly tended to have a healthier diet and less obesity. ${ }^{12}$ Lists may help because they capture some decisions that consumers have already made, reducing a shopper's vulnerability to in-store pitches.

\section{Mitigating Obesity's Public Health Threat}

The obesity epidemic is arguably one of the nation's most serious health threats. It is also a steadily growing contributor to the national health care tab. The RAND studies highlighted here underscore what many public health experts believe: Obesity is a population-level problem that demands population-focused policies. These might include regulation, which successfully limits access to alcohol; standardized portions for restaurant meals so that diners know how much they are being served; or regulations for how food is marketed to consumers.

The bottom line: Obesity is not a one-dimensional problem. And it cannot be successfully confronted with a one-dimensional strategy. It will take more than willpower, increased access to healthy food, or limited access to junk food. The epidemic can only be stemmed by replacing what has been called a "food swamp" with a balanced food environment. ${ }^{13}$

\section{Obesity is not a one-dimensional problem.}

This research highlight summarizes RAND Health research reported in the following publications:

'Sturm R and Hattori A, "Morbid Obesity Rates Continue to Rise Rapidly in the United States," International Journal of Obesity, Vol. 37, No. 6, June 2013, pp. 889-891.

Goldman DP, Cutler DM, Shekelle PG, Bhattacharya J, Shang B, Joyce GF, Hurd MD, Matsui D, Newberry S, Panis C, Rich MW, Su CK, Keeler EB, Lakdawalla DN, Chernew ME, Pan F, Ortiz E, Brook RH, Garber AM, and Rhodes S, "Modeling the Health and Medical Care Spending of the Future Elderly," Santa Monica, Calif.: RAND Corporation, RB-9324, 2008 (www.rand.org/t/RB9324).

${ }^{3}$ Sturm R and Ruopeng A, "Obesity and Economic Environments," CA: A Cancer Journal for Clinicians, Vol. 64, No. 5, September/ October 2014, pp. 337-350

${ }^{4}$ Mejia N, Lightstone AS, Basurto-Davila R, Morales DM, and Sturm R, "Neighborhood Food Environment, Diet, and Obesity Among Los Angeles County Adults, 2011," Preventing Chronic Disease, Vol. 12, E143, September 3, 2015

Dubowitz T, Zenk SN, Ghosh-Dastidar B, Cohen DA, Beckman R, Hunter G, Steiner ED, and Collins RL, "Healthy Food Access for Urban Food Desert Residents: Examination of the Food Environment, Food Purchasing Practices, Diet and BMI," Public Health Nutrition, Vol. 18, No. 12, August 2015, pp. 2220-2230

${ }^{6}$ Ghosh-Dastidar B, Cohen DA, Hunter G, Zenk SN, Huang CY, Beckman R, and Dubowitz T, "Distance to Store, Food Prices, and Obesity in Urban Food Deserts," American Journal of Preventive Medicine, Vol. 47, No. 5, November 2014, pp. 587-595.

Dubowitz T, Ghosh-Dastidar M, Cohen DA, Beckman R, Steiner E, Hunter GP, Florez K, Huang C, Vaughan CA, Sloan JC, Zenk SN, Cummins S, and Collins RL, "Diet and Perceptions Change with Supermarket Introduction in a Food Desert, but Not Because of Supermarket Use," Health Affairs, Vol. 34, No. 11, November 2015, pp. 1858-1868, DOI: 10.1377/hlthaff.2015.0667.

${ }^{8}$ Wu H and Sturm R, "What's on the Menu? A Review of the Energy and Nutritional Content of U.S Chain Restaurant Menus," Public Health Nutrition, Vol. 16, No. 1, January 2013, pp. 87-96.

${ }^{9} \mathrm{Wu} \mathrm{H}$ and Sturm R, "Changes in the Energy and Sodium Content of Main Entrees in US Chain Restaurants from 2010 to 2011," Journal of the Academy of Nutrition and Dietetics, Vol. 114, No. 2, February 2014, pp. 209-221.

${ }^{\circ}$ Cohen D, Collins R, Hunter G, Ghosh-Dastidar B, and Dubowitz T "Store Impulse Marketing Strategies and Body Mass Index," American Journal of Public Health, Vol. 105, No. 7, July 2015, pp. 1446-1452.

Cohen D and Babey S, "Candy at the Cash Register: A Risk Factor for Obesity and Chronic Disease," New England Journal of Medicine Vol. 367, No. 15, October 11, 2012, pp. 1381-1383.

2 Dubowitz T, Cohen D, Huang C, Beckman B, and Collins R, "Using a Grocery List Is Associated with a Healthier Diet and Lower BMI Among Very High-Risk Adults," Journal of Nutrition Education and Behavior, Vol. 47, No. 3, May-June 2015, pp. 259-264.

${ }^{3}$ Cohen D, A Big Fat Crisis: The Hidden Forces Behind the Obesity Epidemic and How to End It, New York: Nation Books, 2014.

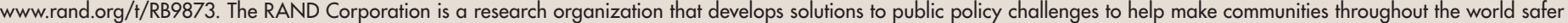

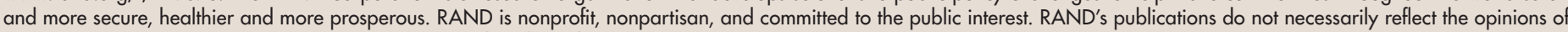
its research clients and sponsors. RAND ${ }^{\circledR}$ is a registered trademark. ๑ RAND 2015

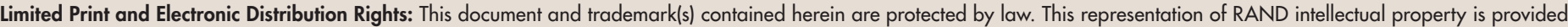

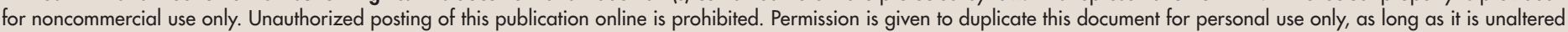

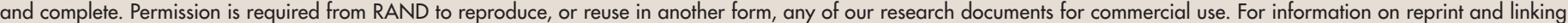
permissions, please visit www.rand.org/pubs/permissions.html. 